\title{
Insights from early COVID-19 responses about promoting sustainable action
}

\author{
Thijs Bouman $\oplus^{1 凶}{ }^{\varpi}$ Linda Steg $\oplus^{1}$ and Thomas Dietz ${ }^{2}$
}

\begin{abstract}
Early in 2020, the coronavirus disease (COVID-19) spread around the world, disrupting lives and societies. In some places, public responses to COVID-19 were remarkably rapid and forceful, particularly in comparison to global environmental crises. What can we learn from these responses to promote mitigation of global environmental crises? We hypothesize that supportive public responses to COVID-19 were partly promoted by strong personal norms: feeling morally compelled and responsible to act. We discuss what aspects of COVID-19 may have engaged antecedents of personal norms, and how these dynamics could be enhanced in global environmental crises to promote their mitigation.
\end{abstract}

A fter its sudden outbreak in late 2019, the new coronavirus disease (COVID-19) quickly spread around the world. The virus causes respiratory illness and poses major and immediate health threats, which strongly disrupted individuals' lives and the functioning of whole societies. The virus spreads through droplets of saliva and discharge from the nose, and transmission can be slowed by strict hygiene practices and limiting social $\operatorname{contact}^{1}$. Such mitigative actions require individual citizens to suddenly change their lifestyles in drastic ways ${ }^{2,3}$. Based on experiences with global sustainability crises (for example, climate change), such changes seem however improbable to achieve. It could therefore appear that the prospects of society dealing effectively with COVID-19 were rather bleak.

Yet, in multiple instances, public responses to COVID-19 have been remarkably well-coordinated, rapid and forceful, particularly at early stages of the crises. For instance, during early COVID-19 outbreaks, some countries enforced strict lockdowns (for example, China, Italy, New Zealand, Philippines and South Africa). Many schools and businesses were shut, and many individuals engaged in strict hygiene practices, social distancing and self-quarantining, which all involve substantial personal and social costs ${ }^{4,5}$. These responses are even more striking given that most individuals feel that risks associated with contracting the virus are greater for others than for themselves ${ }^{6,7}$. Also, knowledge about the virus and its mitigation was, and still is, very uncertain and tentative. How can we explain this strong public engagement in these often drastic mitigative actions? And, importantly, what can we learn from this experience to promote actions to mitigate COVID-19 and other urgent global threats requiring similarly prosocial actions, such as global environmental crises?

We suggest that the relatively rapid and forceful prosocial responses to COVID-19 may partly be explained by strong personal norms to take action, reflecting strong feelings of being personally responsible and morally compelled to $\mathrm{act}^{8}$. A substantial literature has established various factors that activate and strengthen personal norms $s^{8,9}$. We propose that many such factors were strongly engaged in instances where early responses to COVID-19 were rapid and forceful. For many global environmental crises, these factors seem to be far less apparent and countered by other influences, possibly explaining why public responses to global environmental crises are typically less powerful.
Here, we elaborate on which factors may have strengthened personal norms in the COVID-19 crisis, and examine how personal norms for pro-environmental action could be strengthened in a similar way. We first describe what personal norms are, their origins, and why they are key to translating the concerns, beliefs and emotions elicited by a threat into concrete actions. We then outline how in various contexts the early COVID-19 crisis may have strengthened personal norms, and engaged the conditions under which personal norms translate into action. We consider the ways that the pandemic and global environmental crises and how they are managed are similar and different. On the basis of this, we extract lessons from the early COVID-19 crisis for promoting sustainability, and provide a research agenda to identify how personal norms can be strengthened to promote mitigative actions. Importantly, our theory-driven approach moves beyond ad hoc explanations, resulting in more generalizable insights that are pressingly needed to effectively respond to global crises. Even if in the end not all of our arguments prove correct, strong grounding in theory will encourage cumulative understanding for future crises.

\section{Personal norms are key to action}

Personal norms are internalized personal standards for what is morally the right thing to do. They invoke a personal responsibility and moral obligation to take prosocial action ${ }^{8,9}$, which seems just the kind of action that is needed to mitigate global crises. Specifically, many people feel that primarily others rather than themselves are impacted by global crises, including COVID-19 $9^{6,7}$ and global environmental crises like climate change and pollution ${ }^{10,11}$. Hence, individual responses to global crises seem to involve prosocial actions ${ }^{12}$ : actions that are believed as primarily having benefits for others and society, while having limited personal benefits, and sometimes even having substantial personal costs.

Personal norms reflect an intrinsic motivation to take prosocial action; individuals personally want and feel the need to undertake such actions ${ }^{8}$. When individuals act in accordance with their personal norms, they typically feel proud, good and true to themselves. In contrast, not acting in line with one's personal norms often induces feelings of guilt and being untrue to oneself $f^{8,13}$. As personal norms reflect intrinsic motivations, they are a more stable base for action than many extrinsic factors ${ }^{8}$, such as social norms, for which

'Department of Psychology, Faculty of Behavioural and Social Sciences, University of Groningen, Groningen, the Netherlands. ${ }^{2}$ Department of Sociology, Environmental Science and Policy Program, Center for Systems Integration and Sustainability, Michigan State University, East Lansing, MI, USA.

凶e-mail: t.bouman@rug.nl 


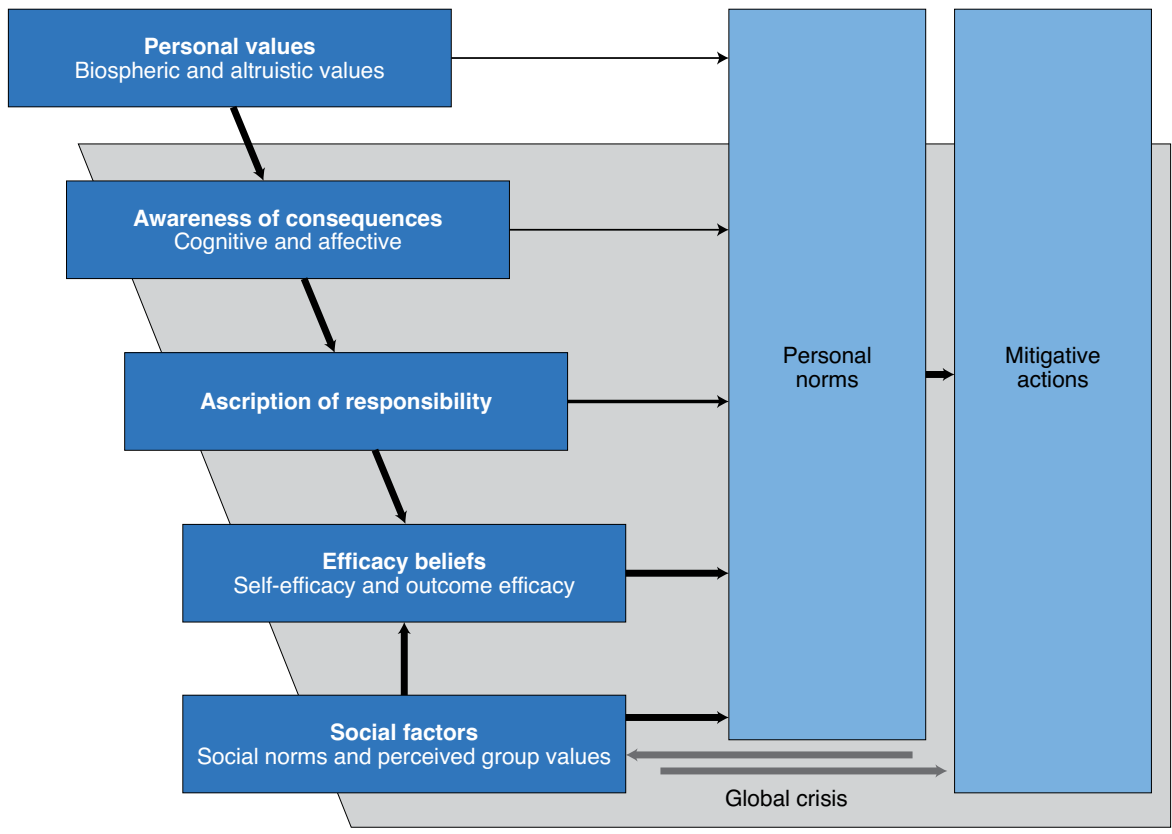

Fig. 1 | Theoretical framework. Theoretical framework of pathways leading to mitigative actions. Black arrows and blue boxes represent the relationships that we hypothesize will lead to initial responses to global crises, and are the focus in this Perspective. Grey arrows represent relationships that we expect will develop based on these initial responses, and are discussed in the section 'Future directions'. Thicker arrows represent stronger relationships.

effectiveness strongly depends on their salience and personal relevance $^{14}$. Indeed, personal norms are typically found to be among the strongest and most consistent predictors of prosocial action ${ }^{15,16}$.

The literature shows that personal norms are at the end of a causal chain and are influenced by several factors (see Fig. 1) ${ }^{9,13}$. A crisis can affect factors in the chain, and thereby influence personal norms and thus the likelihood that someone will support or take mitigating actions. For example, value-belief-norm theory indicates that personal values affect the extent to which people are aware that a crisis might have negative consequences for things they value ${ }^{17}$. This in turn affects how much responsibility individuals ascribe to themselves for contributing to the crisis, and perceive themselves as being able to contribute to the mitigation of the crisis. This, together with individuals' perception of what other people do, appreciate and value (for example, perceived group values and social norms), influence personal norms ${ }^{18}$. We elaborate on these factors below.

Personal values. Values are general and stable goals that function as guiding principles in people's lives ${ }^{19}$. People with stronger altruistic values (that is, caring for others and social justice) and biospheric values (that is, caring for nature and the environment) are likely to have stronger personal norms to take action to mitigate global crises $^{8,20}$. Studies across a variety of nations demonstrate that many individuals strongly endorse altruistic and biospheric values, suggesting there is a relatively strong value base for actions to mitigate global crises ${ }^{18}$. Altruistic and biospheric values mostly affect personal norms indirectly, through factors described below.

Awareness of consequences. One way values influence personal norms is through individuals' awareness of consequences ${ }^{9,21}$, reflecting the extent to which individuals acknowledge (that is, cognitive awareness) and worry about (that is, affective appraisal) the adverse consequences of global crises. Awareness of consequences is an assessment of the risks to things that are valued ${ }^{8}$. It is shaped by how well consequences are known, how easily consequences can be observed, how rapid and severe the consequences are and what is communicated about the consequences. The more individuals acknowledge and worry about the possible adverse consequences of a global problem, the more likely they have strong personal norms. Individuals with strong altruistic and biospheric values are more attuned to negative consequences for others, society and the environment, and are therefore more likely to acknowledge and worry about the negative consequences of a global problem ${ }^{9,22}$. Thus, awareness of consequences links values to personal norms.

Ascription of responsibility. Even if one is aware of adverse consequences of a crisis, personal norms may remain weak if the crisis is seen as caused by forces outside of one's control. Indeed, personal norms are generally stronger the more people believe their actions contribute to the crisis ${ }^{8,9,21}$. In contrast, personal norms are weaker when people feel that others, for example governments and private organizations, are responsible for the problems and their solution ${ }^{23}$. Yet, the latter could lead to a personal norm to influence the actions of those powerful others, perhaps through protests and political action?.

Efficacy beliefs. In addition to ascribing some responsibility to the self, personal norms for action require that individuals believe they can engage in actions to mitigate the crisis (that is, self-efficacy) ${ }^{21,24}$, and that such actions will improve the situation (that is, outcome efficacy, sometimes also referred to as response efficacy $)^{8,9,21}$. When individuals see no better alternatives to current behaviours, perceive alternatives but see no practical means to carry them out, or see alternatives but perceive their impacts to be inconsequential, efficacy beliefs and therefore personal norms are likely weak ${ }^{24}$.

Social factors. Perception of expectations and actions of others can also affect personal norms, particularly when these others are members of a group that an individual strongly identifies with ${ }^{12,25,26}$. Indeed, observing and learning from others strongly influences human action ${ }^{14,27,28}$. Key social factors include perceptions of others' values (that is, perceived group values) ${ }^{18,25,29}$, of what others would approve (that is, injunctive norms) and of what others actually do (that is, descriptive norms) ${ }^{14,30}$. Such social factors reflect what relevant others think is important, right and sensible, that could be internalized into personal norms ${ }^{31}$. Moreover, they may influence 
personal norms indirectly. For example, descriptive norms indicating many people are acting may enhance individuals' outcome efficacy and in turn strengthen personal norms.

Perceptions of what others value, approve and do may be particularly critical in global crises, given that actions to mitigate such crises are often taken to produce collective benefits. So, when others-the beneficiaries of collective action-seem not to care about or act upon a crisis, feelings of moral obligations to act oneself are likely weakened. These are the dynamics of the tragedy of the commons $^{32}$, which appears to be a central aspect in many global crises.

\section{Aspects of crises that strengthen personal norms}

Antecedents of personal norms-and thus responses to global crises-differ depending on various aspects of a crisis. Personal values are an exception since they are relatively stable across one's life course and situations. Factors such as the nature of the onset of a crisis, its complexity and the consequences all may influence action through the causal paths we have outlined. Our theoretical framework may thereby help explain why responses in some situations are more prompt and stronger than for others, and provide key insights into what factors could be enhanced to promote actions to mitigate global crises. In this section, we discuss aspects of the initial stages of the COVID-19 crisis that may have strengthened antecedents of personal norms to take action, how these differ for many global environmental crises, and perhaps between locations and stages of the COVID-19 crisis.

Awareness of consequences. One key aspect that sets the early COVID-19 crisis apart from many global environmental crises is that its consequences are relatively obvious, easy to understand and directly measurable. Moreover, these consequences were clearly and widely communicated in many countries where responses to COVID-19 were rapid and forceful, and were clearly attributed to COVID-19. For instance, many governments and health organizations communicated the number of persons infected and who had died from COVID-19, and presented projections of what might happen without individual mitigative action ${ }^{1}$. This all may explain why many people were well aware of COVID-19's consequences, and worried about $i^{33}$. Consequences of many global environmental crises are less directly evident, and the processes through which these crises lead to adverse outcomes are often subtle, complex and are mostly only visible in the long term. Moreover, many metrics of global environmental crises (for example, $\mathrm{CO}_{2}$ emissions and ecosystems threatened) are less directly observable, less familiar and seem more spatially, temporally and socially distant than the consequences of COVID-19 $9^{34,35}$. Additionally, we conjecture that at the initial stages of the pandemic, before it became politicized in some countries, trust in public health scientists was higher than trust in climate and other environmental scientists ${ }^{36}$, likely resulting in less scepticism about the crisis and more awareness of its consequences.

Roles and responsibilities. The roles and responsibilities of individuals in the COVID-19 crisis and its mitigation seem to be clearer and better defined than in many global environmental crises, which likely enhanced ascription of responsibility. For example, when one knows the virus spreads through droplets of saliva and discharge from the nose, it is relatively self-evident that certain behaviours may contribute to the spreading of the virus. For many global environmental crises, it is more difficult to understand how one's actions may contribute to the crisis. Many individual actions (for example, driving a car or eating meat) impact global environmental crises, but the impacts of single individual actions are typically small, indirect and difficult to understand; for instance, requiring an understanding of embodied impacts (such as the environmental impacts associated with the production, transportation and disposal of a product $)^{37}$. This all likely reduces ascription of responsibility.
Efficacy beliefs. When individuals have a general understanding of how the virus spreads, it is also relatively easy to see what actions one could take to reduce risks of contracting and spreading the virus (for example, hygiene behaviours and maintaining distance), which likely enhanced self-efficacy. Moreover, during the early stages of the outbreak, a small set of these very concrete and coherent actions has been widely and consistently communicated by many national governments and health organizations ${ }^{1}$, which may have further strengthened self-efficacy. In contrast, actions that can help mitigate global environmental crises are typically highly diverse (for example, varying from limiting car use and eating less meat, to buying more efficient equipment) and less consistently communicated, making it more difficult for individuals to understand what actions they could and would need to undertake to mitigate global environmental crises, likely limiting their self-efficacy.

In addition, outcome efficacy was likely higher for COVID-19 than for many global environmental crises. Individuals who engage in actions to mitigate COVID-19 directly limit the chance that they or others in their close vicinity will be infected. Moreover, the effects of such actions when performed collectively (for example, via lockdowns, policies and regulations) can be observed and quantified in a relatively short time frame (for example, reduced number of infections or rate of spread), making the effectiveness of successful measures almost instantly evident. For many global environmental crises, effects of mitigative actions will only be visible if many others take these actions too, and will only be noticeable in a far future, at remote places, which likely reduces outcome efficacy. Many actions to mitigate global environmental crises will also only be able to reduce the problem, rather than solve it, as many consequences are now already apparent and irreversible (for example, climate change and biodiversity loss). Moreover, many processes behind global environmental crises continue after action is taken, and problems will still increase for a long time, even as mitigation efforts unfold ${ }^{38}$. Additionally, the environmental impact of specific individual actions, such as energy-saving behaviours, may not be well understood ${ }^{39}$, creating uncertainties about such actions, which may also decrease outcome efficacy.

Social factors. Regions where responses to the pandemic were widespread seemed to convey strong injunctive and descriptive norms to take mitigative actions, and to signal that many people-including governments and organizations-cared about and worked towards the same goal to mitigate the crisis (that is, perceived group values) (see ref. ${ }^{40}$ ). During lockdowns, regulations required people to stay at home, and many places of gathering were temporarily shut. Those that stayed open often instituted highly visible practices to reduce infection risk of staff and customers. In addition, mitigative actions were facilitated (for example, free tests), and those who were negatively impacted by mitigative actions were supported (for example, facilitating working from home and compensating those with financial losses). For many global environmental crises, such strong, coherent and consistent regulations and norms are missing, and people seem to underestimate how much others care about such crises and their mitigation ${ }^{18,25}$. Moreover, it is typically difficult to observe and know to what extent others engage in different sustainable behaviours as actions are often private, hidden in a larger bundle of practices and no individual is consistently pro-environmental in every action ${ }^{23}$.

Putting things together. In sum, even though there is still much that remains unknown, information about COVID-19 and its mitigation is relatively easy to understand, and seemed to be communicated clearly, consistently and univocally in regions where public responses have been rapid and forceful. Moreover, in these regions, mitigative actions appeared to receive broad and visible support during the crisis's early onset. In contrast, many global 
environmental crises are associated with more uncertainties, and are communicated and managed in less consistent ways. The uncertainties and inconsistencies associated with global environmental crises are partly caused by the more complex nature of such crises, and partly by parties opposing mitigative actions for political reasons $^{41,42}$. Can we learn from those instances where public responses to COVID-19 were well-coordinated, rapid and forceful, particularly to more effectively deal with global environmental crises?

\section{What responses to COVID-19 teach us}

Based on our theoretical analysis of why in various cases public responses to COVID-19 were relatively rapid and forceful compared to global environmental crises, we here suggest how antecedents of personal norms could be strengthened to promote environmental action.

Enhancing general understanding of crises. For many global environmental crises, the link between causes and consequences is more complex and less self-evident than for COVID-19. This suggests we need to strengthen awareness of consequences and ascription of responsibility, and thereby promote personal norms and mitigative actions. To do so, it may be essential to help people understand the system-wide impacts of their actions and associated crises ${ }^{43,44}$, both globally and locally, without making the situation overly complex. Many global environmental crises involve complex systems of cause and effect, and members of the public are unlikely to follow the intricacies of these dynamics. But it may be sufficient to make clear what actions are of greatest consequence, and to highlight the most critical causal paths and system-wide impacts of these actions and associated global crises.

Such strategies may have also further promoted mitigative actions during the COVID-19 crisis. Making people aware that the pandemic has disruptive impacts on social and economic systems, along with threatening people's health, likely strengthened individuals' motivation to act ${ }^{45}$. Specifically, such understanding gives people more diverse reasons to act, which may be particularly relevant for those people less concerned about personal health consequences. Similarly, pointing out the wider social, economic and national security consequences of global environmental crises may strengthen individuals' motivation to take pro-environmental action. This may be particularly critical to motivate those individuals who care little about the consequences for nature and the environment ${ }^{38}$.

Enhancing personal relevance. Another likely explanation for why responses to the early COVID-19 crisis were rapid and forceful in some places is that communication made clear that many of the outcomes of the crisis were highly personally relevant and meaningful (for example, hospitalizations and deaths, often reported at a national or regional level). For many global environmental crises, outcomes are considered socially, temporally and spatially remote. If these consequences would seem more psychologically close and relevant, action is more likely. One way to achieve this is by quantifying the crises with metrics that are more meaningful to people (for example, lives threatened, endangered species or natural areas lost $)^{38}$, instead of by the more abstract or physical metrics often employed (for example, $\mathrm{CO}_{2}$ emissions and temperature increase). Such information likely enhances individuals to acknowledge the consequences and worry about them, as individuals become more aware that a crisis impacts things or persons they personally value ${ }^{22}$. For instance, worries about plastics may increase when people know how plastics affect local ecosystems, the food they consume, and their own and others' health and animals they care about.

Focusing on the impacts that individuals can easily relate to, and that affect them personally, may also increase the personal relevance of global environmental crises $^{34,35}$. In addition to enhancing awareness of consequences, such efforts may enhance ascription of responsibility and self-efficacy since showing the personal relevance of global crises may make individuals' contributions to a crisis more concrete, observable and understandable. Of particular importance is demonstrating that actions both as a consumer and as a citizen matter.

Highlighting shared prosocial motivation. It is important to clearly and widely communicate that many individuals deeply care about the lives and things being affected by global environmental crises, and strongly support actions to mitigate such crises, as was often clear early in the COVID-19 crisis. Such communication may be particularly critical to correct common misperceptions about others not caring much about nature, the environment and prosocial action ${ }^{18,25,46}$ (see subsection 'Social factors' in the 'Aspects of crises that strengthen personal norms' section). These misperceptions may reduce individuals' outcome efficacy and motivation to engage in mitigative actions ${ }^{18}$, and may restrain action by politicians and other leaders to act because of a lack of perceived public support $^{47}$. Indeed, making people aware of others' sustainable actions ${ }^{30}$ or a group's sustainable aims (for example, corporate environmental responsibility $)^{48}$ may motivate individuals to take mitigative actions. Such strategies may be particularly powerful for motivating those individuals who are not strongly personally motivated ${ }^{25,48}$. In addition, highlighting the consensus about the existence of global crises may counter the effects of 'disinformation' ${ }^{49}$, and may thereby enhance public engagement in mitigative actions.

Supportive policies and regulations. It is important to note that actions by individuals are seldom sufficient to mitigate global crises. Actions by governments and the private sector are also essential, as they can create conditions that make mitigative actions more feasible and attractive ${ }^{1,38}$. Early in the COVID-19 crisis, various governments and companies supported individuals in taking mitigative action (for example, facilitating working from home and home deliveries), and compensated those who were hit hardest by mitigative actions (for example, those who lost income), which may have enhanced public engagement in mitigative actions. Similar measures could be implemented to compensate those who would suffer from mitigating global environmental crises, such as supporting fossil-based industries and workers to transition to renewables, and facilitating individuals to perform sustainable behaviour and buffering them for increased costs associated with those behaviours ${ }^{50,51}$. As was the case for COVID-19, strong, trusted leadership is needed to support mitigative actions at all levels of society ${ }^{38}$.

Actions by governments and the private sector may also be critical to increase outcome efficacy and personal norms to take action to mitigate global crises. Most global environmental crises can only be addressed through multiple mitigative actions taken collectively by individuals and groups at all levels of society, but particularly by action in economically developed countries. Accordingly, strong and concrete commitments to take action from countries and private organizations across the world likely enhances individuals' beliefs that their actions will contribute, be impactful and yield positive effects, instead of giving them the impression that their actions are isolated and futile.

Creating win-win situations. COVID-19, global environmental crises and the actions to address them interact. For example, during lockdowns less motorized travel occurred and less energy was used $^{52,53}$, reducing emissions and bringing wildlife to otherwise crowded areas. Yet, COVID-19 mitigation measures also lowered the proportion of commuters that use public transportation, which over the long run may interfere with environmental goals (that is, creating trade-offs) ${ }^{54}$. Moreover, the economic costs of COVID-19 mitigation measures may hold people, companies and governments 
back from investing in sustainability ${ }^{55}$. Similarly, responses to global environmental crises may impact pandemics such as COVID-19. Ecosystem alterations and wildlife exploitation increase the likelihood that pandemics occur, suggesting pro-environmental actions can prevent future pandemics ${ }^{56-58}$. Such synergies and trade-offs should be carefully considered when designing mitigation strategies, in which mitigation measures with synergies rather than trade-offs should be prioritized. Critically, prioritizing win-win solutions may not only contribute to solving two (or more) crises at once, but may also receive wider support, motivating individuals with diverse goals.

\section{Future directions}

By employing our theoretical model to analyse the early stages of the COVID-19 crisis, we identified what we consider to be key lessons learned that could assist with promoting more rapid, forceful and effective mitigative actions. These lessons can be treated both as tentative guidance for future actions and as hypotheses to be tested. There is an urgent need to examine how these crises evolve over time, are managed, and how this affects personal norms and their antecedents, other relevant factors and mitigative actions. We suggest five main directions for future research.

Variation in strategies across locations. Whereas public responses to early outbreaks of COVID-19 were in many places relatively rapid and forceful, particularly when compared to other global crises, this was not the case everywhere. Some of this variation may be due to how COVID-19 was managed. Specifically, regional strategies may have differed in how effectively they engaged the factors of our theoretical model, which may explain differences in responses. For instance, while in many countries messages about COVID-19's outcomes and mitigation were relatively clear and consistent, there were also countries in which messages appeared more mixed (for example, Brazil, the United Kingdom and the United States), which may have lowered awareness of consequences and efficacy beliefs, thereby weakening personal norms and mitigative actions. Similarly, there has been variation in whether and how countries enforced mitigative action. Some countries enforced strict testing procedures and lockdowns, while others relied more on people's intrinsic motivations to engage in advocated mitigative actions, such as the personal values and personal norms in our model. Whereas strict regulations may be important to ensure rapid change in response to a new crisis like COVID-19, we reason based on our theoretical model that more durable change is unlikely unless regulations are internalized into personal norms. Enforcement would therefore need to be accompanied with strategies that foster intrinsic motivation to act, for instance by targeting the different factors of our theoretical model. Now is the time to collect data to evaluate the impacts of different (combinations of) strategies, and to examine whether and how they affect the variables in our theoretical model and, thereby, promote mitigative action. Such endeavours will enable the identification of key strategies and factors that can most effectively and consistently promote the mitigative actions needed, and thereby critically contribute to more effective responses to future COVID-19 outbreaks, as well as to other global crises.

Variation in dynamics over time. The COVID-19 crisis hit nations hard and suddenly, and although some prospects are improving in many places, the future is still highly uncertain and variable across countries ${ }^{59}$. How will aspects of the crisis, and thereby antecedents of personal norms, change over time? For instance, as the COVID19 crisis continues for a longer period of time, risks may seem more gradual, potentially reducing worry and personal norms. Indeed, in many countries where infection rates went down, restrictions were quickly eased and many people rapidly returned to old practices, apparently feeling little moral obligation to continue mitigative actions. Some of this may have been the result of efforts to politicize responses, breaking the sense of social consensus. Also, some of it may be due to self-interest in returning to life as normal, eventually eroding prosocial motivations. Our theoretical framework can be used to generate these and other hypotheses about change over time. Testing such hypotheses while crises develop may assist in selecting strategies to safely ease, or quickly reinforce mitigative actions when appropriate.

Expanding the framework. We focused on personal norms and their well-established antecedents because of their strong and consistent relationship with mitigative actions. Yet, other factors and relationships obviously also play a role in motivating mitigative action, and may become more important at other stages of a crisis. Future studies could expand our framework, and further test the dynamics between factors. For instance, when many individuals start to engage in mitigative actions-possibly because of their personal norms - strong descriptive norms to take mitigative action may develop ${ }^{18}$. These descriptive norms may in turn directly, as well as indirectly via personal norms, affect mitigative behaviour, particularly in public settings. Longitudinal data on such responses to global crises are needed to test such dynamic relationships, and to examine how pathways to action develop over time, which may be particularly valuable to develop long-term mitigation strategies.

Testing our framework across crises. Research is needed to specify the degree to which personal norms and their antecedents are engaged across different crises, and whether this explains the difference in the degree to which mitigative actions are taken. Specifically, we need to understand what aspects of crises strengthen which antecedents of personal norms and mitigative actions, and to what degree the hypothesized relationships generalize across crises. Studies comparing responses to different crises while employing consistent theoretical frameworks such as ours are essential to identify effective and generalizable ways to encourage mitigative actions.

Synergies and trade-offs between mitigation goals. Research is needed on the system-wide impacts of global crises and their mitigative actions. Specifically, systems thinking ${ }^{43,44}$ teaches us that one crisis or mitigative action usually has diverse effects throughout coupled human and natural systems. Interdisciplinary research is needed to identify these system-wide outcomes, and to develop win-win strategies that are beneficial across the board and, when that is not possible, to be clear about trade-offs. Such strategies are likely to increase public support and adoption rates, which further enhances their effectiveness. Of particular importance is paying careful attention to equity effects, as both global crises and the mitigation efforts developed to respond could have unequal and unjust impacts. Yet, recent assessments suggest that many mitigation actions have beneficial effects for diverse sustainable development goals, which is highly promising for the promotion of sustainable action $^{38}$.

\section{Conclusions}

Initial responses to COVID-19 tell us that drastic transformative change is possible and sometimes acceptable to many individuals. We propose that certain aspects of the COVID-19 crisis strengthened the engagement of personal norms and their antecedents, which may partially explain the rapid and forceful response observed. By applying our theoretical framework to the COVID-19 crisis, we offer insights into ways to motivate the actions needed to mitigate other urgent global crises, including global environmental crises. Although the individual-level responses of the sort that are our focus here are never sufficient to resolve global crises, they can be immensely important in shifting the trajectory of a crisis. In turn, they must be supported and re-enforced by system-wide action by 
government and private organizations. Now is the time to refine and test theoretical frameworks, such as the one we propose, to understand these crises dynamics.

Received: 8 June 2020; Accepted: 18 September 2020;

Published online: 12 October 2020

\section{References}

1. Coronavirus Disease 2019 (World Health Organization, 2020); https:// go.nature.com/2EqcE9K

2. Van Bavel, J. J. et al. Using social and behavioural science to support COVID-19 pandemic response. Nat. Hum. Behav. 4, 460-471 (2020).

3. West, R., Michie, S., Rubin, G. J. \& Amlôt, R. Applying principles of behaviour change to reduce SARS-CoV-2 transmission. Nat. Hum. Behav. 4, 451-459 (2020).

4. Brooks, S. K. et al. The psychological impact of quarantine and how to reduce it: rapid review of the evidence. Lancet 395, 912-920 (2020).

5. Guan, D. et al. Global supply-chain effects of COVID-19 control measures. Nat. Hum. Behav. 4, 577-587 (2020)

6. Coronavirus: Opinion and Reaction (Ipsos, 2020).

7. COVID-19: Views of Outbreak Impact (Pew Research Center, 2020); https:// go.nature.com/344HSfB

8. Steg, L. Values, norms, and intrinsic motivation to act proenvironmentally. Annu. Rev. Environ. Resour. 41, 277-292 (2016).

9. Stern, P. C. New environmental theories: toward a coherent theory of environmentally significant behavior. J. Soc. Issues 56, 407-424 (2000)

10. Schultz, P. W. The structure of environmental concern: concern for self, other people, and the biosphere. J. Environ. Psychol. 21, 327-339 (2001).

11. Tvinnereim, E. et al. Climate change risk perceptions and the problem of scale: evidence from cross-national survey experiments. Environ. Politics https://doi.org/10.1080/09644016.2019.1708538 (2020).

12. Jetten, J., Reicher, S. D., Haslam, A. \& Cruwys, T. Together Apart: The Psychology of COVID-19 (SAGE Publications Ltd, 2020)

13. Schwartz, S. H. in Advances in Experimental Social Psychology Vol. 10 (ed. Berkowitz, L.) 221-279 (Academic Press, 1977).

14. Cialdini, R. B., Reno, R. R. \& Kallgren, C. A. A focus theory of normative conduct: recycling the concept of norms to reduce littering in public places. J. Pers. Soc. Psychol. 58, 1015-1026 (1990).

15. Bamberg, S. \& Möser, G. Twenty years after Hines, Hungerford, and Tomera: a new meta-analysis of psycho-social determinants of pro-environmental behaviour. J. Environ. Psychol. 27, 14-25 (2007).

16. Niemiec, R. M., Champine, V., Vaske, J. J. \& Mertens, A. Does the impact of norms vary by type of norm and type of conservation behavior? A meta-analysis. Soc. Nat. Resour. 33, 1024-1040 (2020).

17. Stern, P. C., Dietz, T., Abel, T., Guagnano, G. A. \& Kalof, L. A value-belief-norm theory of support for social movements: the case of environmentalism. Hum. Ecol. Rev. 6, 81-97 (1999).

18. Bouman, T. \& Steg, L. Motivating society-wide pro-environmental change. One Earth 1, 27-30 (2019)

19. Schwartz, S. H. Universals in the content and structure of values: theoretical advances and empirical tests in 20 countries. Adv. Exp. Soc. Psychol. 25, $1-65$ (1992).

20. Dietz, T. in Handbook of Value (eds Brosch, T. \& Sander, D.) 329-350 (Oxford Univ. Press, 2015).

21. Steg, L., Bolderdijk, J. W., Keizer, K., Perlaviciute, G. \& Bolderdijk An integrated framework for encouraging pro-environmental behaviour: the role of values, situational factors and goals. J. Environ. Psychol. $\mathbf{3 8}$, 104-115 (2014).

22. Bouman, T. et al. When worry about climate change leads to climate action how values, worry and personal responsibility relate to various climate actions. Glob. Environ. Change 62, 102061 (2020).

23. Lindenberg, S. \& Steg, L. Normative, gain and hedonic goal frames guiding environmental behavior. J. Soc. Issues 63, 117-137 (2007)

24. Harland, P., Staats, H. \& Wilke, H. A. M. Situational and personality factors as direct or personal norm mediated predictors of pro-environmental behavior: questions derived from norm-activation theory. Basic Appl. Soc. Psychol. 29, 323-334 (2007).

25. Bouman, T., Steg, L. \& Johnson-Zawadzki, S. The value of what others value: when perceived biospheric group values influence individuals' pro-environmental engagement. J. Environ. Psychol. 71, 101470 (2020).

26. Fielding, K. S. \& Hornsey, M. J. A social identity analysis of climate change and environmental attitudes and behaviors: insights and opportunities. Front. Psychol. 7, 121 (2016).

27. Henrich, J. The Secret of Our Success: How Culture Is Driving Human Evolution, Domesticating Our Species, and Making Us Smarter. The Secret of Our Success (Princeton Univ. Press, 2019).

28. Frank, R. H. Under the Influence: Putting Peer Pressure to Work (Princeton Univ. Press, 2020).
29. Wolf, L. J., Haddock, G., Manstead, A. S. R. \& Maio, G. R. The importance of (shared) human values for containing the COVID-19 pandemic. Br. J. Soc. Psychol. 59, 618-627 (2020).

30. Schultz, P. W., Nolan, J. M., Cialdini, R. B., Goldstein, N. J. \& Griskevicius, V. The constructive, destructive, and reconstructive power of social norms. Psychol. Sci. 18, 429-434 (2007).

31. Thøgersen, J. Norms for environmentally responsible behaviour: an extended taxonomy. J. Environ. Psychol. 26, 247-261 (2006).

32. Dietz, T., Ostrom, E. \& Stern, P. C. The struggle to govern the commons. Science 302, 1907-1912 (2003).

33. COVID-19: Emotional Impact (Pew Research Center, 2020); https://go.nature. com/2S7IGL6

34. Spence, A., Poortinga, W. \& Pidgeon, N. The psychological distance of climate change. Risk Anal. 32, 957-972 (2012).

35. Brügger, A., Dessai, S., Devine-Wright, P., Morton, T. A. \& Pidgeon, N. F. Psychological responses to the proximity of climate change. Nat. Clim. Change 5, 1031-1037 (2015).

36. Hamilton, L. C., Hartter, J. \& Saito, K. Trust in scientists on climate change and vaccines. SAGE Open 5, 1-13 (2015)

37. Hirsh, J. L., Costello, M. S. \& Fuqua, R. W. Analysis of delay discounting as a psychological measure of sustainable behavior. Behav. Soc. Issues 24, 187-202 (2015).

38. IPCC Special Report on Global Warming of $1.5^{\circ} \mathrm{C}$ (eds Masson-Delmotte, V. et al.) (WMO, 2018).

39. Attari, S. Z., DeKay, M. L., Davidson, C. I. \& De Bruin, W. B. Public perceptions of energy consumption and savings. Proc. Natl Acad. Sci. USA 107, 16054-16059 (2010).

40. Howarth, C. et al. Building a social mandate for climate action: lessons from COVID-19. Environ. Resour. Econ. 76, 1107-1115 (2020).

41. McCright, A. M., Marquart-Pyatt, S. T., Shwom, R. L., Brechin, S. R. \& Allen, S. Ideology, capitalism, and climate: explaining public views about climate change in the United States. Energy Res. Soc. Sci. 21, 180-189 (2016).

42. Michaels, D. The Triumph of Doubt: Dark Money and the Science of Deception (Oxford Univ. Press, 2020).

43. Berry, H. L., Waite, T. D., Dear, K. B. G., Capon, A. G. \& Murray, V. The case for systems thinking about climate change and mental health. Nat. Clim. Change 8, 282-290 (2018).

44. Randle, J. M. \& Stroink, M. L. The development and initial validation of the paradigm of systems thinking. Syst. Res. Behav. Sci. 35, 645-657 (2018)

45. Bradley, D. T., Mansouri, M. A., Kee, F. \& Garcia, L. M. T. A systems approach to preventing and responding to COVID-19. EClinicalMedicine 21, 100325 (2020).

46. Sanderson, R. et al. Strangers in a strange land: relations between perceptions of others' values and both civic engagement and cultural estrangement. Front. Psychol. 10, 559 (2019).

47. Bouman, T. \& Steg, L. Engaging city residents in climate action: addressing the personal and group value-base behind residents' climate action. Urbanisation https://doi.org/10.1177/2455747120965197 (2020).

48. Ruepert, A. M., Keizer, K. \& Steg, L. The relationship between corporate environmental responsibility, employees' biospheric values and pro-environmental behaviour at work. J. Environ. Psychol. 54, 65-78 (2017)

49. van der Linden, S., Leiserowitz, A., Rosenthal, S. \& Maibach, E. Inoculating the public against misinformation about climate change. Glob. Chall. 1, 1600008 (2017).

50. Schuitema, G. \& Steg, L. The role of revenue use in the acceptability of transport pricing policies. Transp. Res. F 11, 221-231 (2008).

51. Jakob, M. et al. Carbon pricing revenues could close infrastructure access gaps. World Dev. 84, 254-265 (2016).

52. Gillingham, K. T., Knittel, C. R., Li, J., Ovaere, M. \& Reguant, M. The Short-run and long-run effects of Covid-19 on energy and the environment. Joule 4, 1337-1341 (2020).

53. Muhammad, S., Long, X. \& Salman, M. COVID-19 pandemic and environmental pollution: a blessing in disguise? Sci. Total Environ. 728, $138820(2020)$

54. De Vos, J. The effect of COVID-19 and subsequent social distancing on travel behavior. Transp. Res. Interdiscip. Persp. 5, 100121 (2020).

55. Ecker, U. K. H. et al. Using the COVID-19 economic crisis to frame climate change as a secondary issue reduces mitigation support. J. Environ. Psychol. 70, 101464 (2020).

56. Afelt, A., Frutos, R. \& Devaux, C. Bats, coronaviruses, and deforestation: toward the emergence of novel infectious diseases? Front. Microbiol. 9, 702 (2018).

57. Dobson, A. P. et al. Ecology and economics for pandemic prevention. Science 369, 379-381 (2020).

58. Nuñez, M. A., Pauchard, A. \& Ricciardi, A. Invasion science and the global spread of SARS-CoV-2. Trends Ecol. Evol. 35, 642-645 (2020).

59. Scudellari, M. How the pandemic might play out in 2021 and beyond. Nature 584, 22-25 (2020) 


\section{Author contributions}

T.B. led the conception and writing of the manuscript, L.S. and T.D. substantially contributed to the conception and writing of the manuscript.

\section{Competing interests}

The authors declare no competing interests.

\section{Additional information}

Correspondence should be addressed to T.B.

Reprints and permissions information is available at www.nature.com/reprints.

Publisher's note Springer Nature remains neutral with regard to jurisdictional claims in published maps and institutional affiliations.

(c) Springer Nature Limited 2020 